IZA DP No. 5405

Globalization and Strategic Research Investments

Anna Bohnstedt

Christian Schwarz

Jens Suedekum

December 2010 


\title{
Globalization and Strategic Research Investments
}

\author{
Anna Bohnstedt \\ University of Duisburg-Essen \\ Christian Schwarz \\ University of Duisburg-Essen \\ Jens Suedekum \\ University of Duisburg-Essen \\ and IZA
}

\author{
Discussion Paper No. 5405 \\ December 2010
}

\author{
IZA \\ P.O. Box 7240 \\ 53072 Bonn \\ Germany \\ Phone: +49-228-3894-0 \\ Fax: +49-228-3894-180 \\ E-mail: iza@iza.org
}

\begin{abstract}
Any opinions expressed here are those of the author(s) and not those of IZA. Research published in this series may include views on policy, but the institute itself takes no institutional policy positions.

The Institute for the Study of Labor (IZA) in Bonn is a local and virtual international research center and a place of communication between science, politics and business. IZA is an independent nonprofit organization supported by Deutsche Post Foundation. The center is associated with the University of Bonn and offers a stimulating research environment through its international network, workshops and conferences, data service, project support, research visits and doctoral program. IZA engages in (i) original and internationally competitive research in all fields of labor economics, (ii) development of policy concepts, and (iii) dissemination of research results and concepts to the interested public.
\end{abstract}

IZA Discussion Papers often represent preliminary work and are circulated to encourage discussion. Citation of such a paper should account for its provisional character. A revised version may be available directly from the author. 
IZA Discussion Paper No. 5405

December 2010

\section{ABSTRACT}

\section{Globalization and Strategic Research Investments ${ }^{*}$}

We develop a general equilibrium model of international trade with heterogeneous firms, where countries can invest into basic research to improve their technological potential. These research investments tighten firm selection and raise the average productivity of firms in the market, thereby implying lower consumer prices and higher welfare. In an open economy, there is also a strategic investment motive since a higher technological potential gives domestic firms a competitive advantage in trade. Countries tend to over-invest due to this strategic motive. There are thus welfare gains from coordinating research investments. The over-investment problem turns to an under-investment problem if there are sufficiently strong cross-country spillovers of basic research investments.

JEL Classification: F12, F13

Keywords: $\quad$ public research investments, public R\&D, international trade, heterogeneous firms, basic research, strategic trade policy

Corresponding author:

Jens Suedekum

Mercator School of Management

University of Duisburg-Essen

Lotharstrasse 65

47057 Duisburg

Germany

Email: jens.suedekum@uni-due.de

\footnotetext{
* We thank Rainald Borck, Anthony Creane, Albert De Vaal, Michael Pflueger, and seminar participants in Passau and at the ETSG in Lausanne for helpful comments and suggestions. All errors and shortcomings are solely our responsibility. We also thank Verena Nowak for excellent research assistance.
} 


\section{Introduction}

Investments into research and development are an important spending item. Table 1 reports the gross domestic expenditure on research and development (GERD) as a share of gross domestic product (GDP) in 21 OECD countries. These R\&D spending shares differ vastly even within the OECD: some countries spend just about 1 per cent, while countries like Sweden, Finland or Korea devote much larger shares of their national income to R\&D expenditures. A substantial share of these expenditures is financed publically with taxpayers' money. This includes purely public research projects and higher education spending, as well as subsidies to private R\&D, innovation funds, and so on. Typically, the public share of the total GERD exceeds one third and moves up to more than two thirds in some countries, which adds up to considerable per-capita amounts that governments spend annually for R\&D purposes. As Table 1 shows, this public research expenditure has increased in almost all OECD countries during the recent time period from 2000 to 2007/08, the Netherlands and Japan being two exceptions. That is, public spending on research and development has apparently become more important over time, and now looms higher on policy agendas than it was the case about 10 years ago.

\section{Table 1 here}

It is well understood that $R \& D$ investments are a key ingredient of sustained economic growth, as they raise the amount of innovation in an economy (Grossman and Helpman 1991). It is also well understood why governments are heavily involved in the financing of basic research, since the public good characteristics of knowledge and ideas tend to jeopardize private investment incentives (Nelson 1950). What is less well understood in the literature, however, is how international trade affects the incentives of a government to strategically invest into the country's technological potential by supporting basic research or conducting public R\&D. There seems to be a widespread perception among policymakers that such public R\&D investments become increasingly important in a world with falling trade barriers, since developed countries perceive the need to support domestic firms in maintaining competitiveness on global markets. ${ }^{1}$ Yet, to the best of our knowledge, there is no theoretical literature which has formally studied these issues.

\footnotetext{
${ }^{1}$ See, for example, the Conclusions of the Council of the European Union (2008): "Providing high-quality education and investing more and more efficiently in human capital and creativity throughout people's lives are crucial conditions for Europe's success in a globalized world" (p.9). Also see Zhou and Leydesdorff (2006) for a discussion that particularly emphasizes the role of China's rise in the world economy in that regard.
} 
In this paper, we develop a two-country general equilibrium model of trade with heterogeneous firms à la Melitz (2003). ${ }^{2}$ In our framework, entrepreneurs can enter a monopolistically competitive manufacturing industry subject to a sunk cost. Upon entry, they randomly draw their productivity level from a known distribution. As in Demidova (2008), we consider this distribution to be country-specific, but in contrast to that paper we allow for endogenous technology differences across countries. In particular, the government of either country can invest into basic research. These research investments raise the country's technological potential, which is modelled as a right-shift of the support of the distribution from which the domestic entrants draw their productivity level. By raising the technological potential of a country, these public investments initially lead to an increase in the expected value of entry. Entrepreneurs still face uncertainty about their individual productivity, and may end up with a draw that is too low to be able to remain in the market. The public research investments therefore do not offset idiosyncratic risks of business failure, which is consistent with the evidence that even the most highly developed and advanced economies (like the US, Germany or Japan) are characterized by substantial exit and churning rates among firms (Geroski 1995). If these investments do not benefit every firm ex post, they do raise the ex ante premises for entrepreneurs, however. Understanding the underlying mechanisms of this policy thus necessarily requires a model with firm heterogeneity and ex ante uncertainty among entrants. ${ }^{3}$

The motive for public research investments in our model is that the increase in the country's technological potential eventually leads to tighter firm selection and higher average productivity of firms, which in turn lowers prices and raises welfare in equilibrium. In the open economy, there is an additional strategic motive. If one country invests more than the other, this yields tougher selection in the leading and softer selection in the laggard country. Exporting becomes easier for firms from the leading country, as the export market is now easier to capture. Firms from the laggard country face tougher competition in their home market, and exporting becomes more difficult. Public research investments

\footnotetext{
${ }^{2}$ It is a well-established empirical fact that there is substantial firm heterogeneity even in narrowly defined industries in such dimensions as productivity, size, or export activity. See, e.g., the empirical studies by Bernard and Jensen (1999), Aw et al. (2000), or Clerides et al. (1998). This empirical observation has triggered a large theoretical literature on trade with heterogeneous firms, e.g. Melitz (2003), Bernard et al. (2003), Melitz and Ottaviano (2008), Demidova (2008). Strategic investments into a country's technological potential have not yet been considered in that literature, however.

${ }^{3}$ In a model with homogeneous firms and without ex ante uncertainty, such as Krugman (1980), a technological improvement would be tantamount to a decrease in marginal costs of all firms. Our model highlights different features, as it is crucially based on the extensive margin of firms' entry, survival, and exporting activities.
} 
thus give domestic firms - on average - a competitive advantage, and countries tend to invest more the higher the level of trade openness is. This result is consistent with the empirical observation that almost all OECD countries have raised R\&D spending during a period that was characterized by falling trade barriers. From a normative perspective, the investments induce a negative cross-country externality so that single countries overinvest. There are thus welfare gains from supranational coordination of public research investments. We also allow for direct $R \& D$ spillovers across countries, following a huge literature that has studied R\&D spillovers across firms. ${ }^{4}$ That is, the public research investment in one country may, to some extent, also raise the technological potential of the other country, because the generated knowledge becomes at least partly accessible across the border. With cross-country spillovers the socially optimal investment level is higher the freer trade is, and the over-investment problem is reduced and may even turn to an under-investment problem if the spillover is strong enough.

This paper is related to the large literature on public investments into research and development, e.g., Gonzales and Pazo (2008), Kleer (2008). We add to this literature by analyzing the positive and normative consequences of those investments in an open economies context, and by studying how trade liberalization affects the strategic investment incentives in general equilibrium. Our paper is also related to the small but growing literature on policy issues in models of international trade with heterogeneous firms, e.g. Demidova and Rodriguez-Clare (2009), Chor (2009), or Pflueger and Suedekum (2009). However, no paper has so far considered government investments into basic research and endogenous cross-country differences in technological potentials. Finally, our paper is related to the literature on international tax competition. The typical setup of those models is that jurisdictions compete for mobile factors or firms, and there is an extensive discussion whether tax competition then leads to under- or over-provision of public goods (e.g., Zoodrow and Mieszkowski 1986, Bénassy-Quéré et al. 2005). Our framework differs in two important respects. First, there is no cross-country mobility but all policy effects are transmitted via (costly) trade. Second and more importantly, though one may think of the research investments as the provision of a public good that makes firms (on average) more productive, our analysis relies crucially on firm heterogeneity and ex ante uncertainty features that have been rarely studied in the tax competition literature so far. ${ }^{5}$

\footnotetext{
${ }^{4}$ See, e.g., Cohen and Levinthal (1989), Jaffe (1989), Adams (1990), Jaffe et al. (1998), O’Mahony and Vecci (2009).

${ }^{5}$ The recent papers by Davies and Eckel (2009) and Krautheim and Schmidt-Eisenlohr (2010) are exceptions, but they do not consider public research investments and their trade-mediated effects.
} 
The rest of this paper is organized as follows. In section 2 we consider a closed economy version of our model, and in section 3 we introduce the open economy setting. Section 4 derives the Nash-equilibrium and the cooperative policy for the case without direct crosscountry spillovers, while section 5 considers the case with spillovers. Section 6 concludes.

\section{Closed Economy}

We first consider a closed economy which is populated by $L$ workers who inelastically supply one unit of labor each. Labor is the only factor of production and perfectly mobile across two industries: a homogeneous goods sector $A$ with constant returns to scale and perfect competition, and a manufacturing industry $C$ which is monopolistically competitive and consists of a continuum of differentiated varieties. Each variety is produced by a single firm under increasing returns to scale, and the firms are heterogeneous in their productivities.

\section{$2.1 \quad$ Preferences}

The preferences of a household $h$ are defined over the homogeneous good, which is used as the numeraire, and the set of differentiated varieties $\Omega$. Utility is represented by a quasilinear, logarithmic function with constant elasticity of substitution (CES) subutility over the set of varieties:

$$
U=\beta \ln C^{h}+A^{h} \quad \text { with } \quad C^{h}=\left(\int_{z \in \Omega} q^{h}(z)^{\rho} \mathrm{d} z\right)^{1 / \rho},
$$

where $0<\rho<1$ and $\beta>0$. The household's consumption of a variety $z$ is given by $q^{h}(z)$. The elasticity of substitution between any two varieties is given by $\sigma \equiv 1 /(1-\rho)$. The CES price index for the bundle of varieties can then be derived in the standard way, and reads as $P=\left(\int_{z \in \Omega} p(z)^{1-\rho} \mathrm{d} z\right)^{1 /(1-\sigma)}$. Utility maximization implies per-capita expenditures $P C^{h}=\beta$ and $A^{h}=y^{h}-\beta$ for the manufacturing aggregate and the homogeneous good, respectively. We assume that $\beta<y^{h}$, i.e., that the preference for varieties is not too large. Indirect utility is then given by:

$$
V^{h}=y^{h}-\beta \ln P+\beta(\ln \beta-1) .
$$

We drop the index $h$ from now on as all households are identical. Total demand and revenue for a single variety $z$ can then be computed as $q(z)=\beta L p(z)^{-\sigma} P^{\sigma-1}$ and $r(z)=p(z) q(z)=\beta L(P / p(z))^{\sigma-1}$, respectively. 


\subsection{Production and Firm Behavior}

In sector $A$ one unit of labor is transformed into one unit of output. Since the price for that good is normalized to one, and since workers are mobile across sectors, this implies that the wage in the closed economy is also equal to one. In the manufacturing industry, a firm needs $l=f+q / \varphi$ units of labor to produce $q$ units of output. The overhead cost $f$ is the same, but the marginal costs $1 / \varphi$ are heterogeneous across firms. A higher value of $\varphi$ represents a higher firm-level productivity. Firms have zero mass and thus take the price index $P$ as given. Since consumers have iso-elastic demands, it is straightforward to see that firms charge prices which are constant mark-ups over firm-specific marginal costs, $p(\varphi)=1 /(\rho \varphi)$. As firms differ only in productivity, total demand and revenue for a single variety can be rewritten as $q(\varphi)=\beta L(\rho \varphi)^{\sigma} P^{\sigma-1}$ and $r(\varphi)=\beta L(\rho \varphi P)^{\sigma-1}$, respectively, and profits are given by $\pi(\varphi)=r(\varphi) / \sigma-f$. It is evident that a firm with a higher productivity charges a lower price, sells a larger quantity, and has higher revenue and profits. The CES price index can be rewritten as follows:

$$
P=M^{1 /(1-\sigma)} p(\widetilde{\varphi})=M^{1 /(1-\sigma)} \frac{1}{\rho \widetilde{\varphi}} \quad \text { with } \quad \widetilde{\varphi} \equiv\left[\int_{0}^{\infty} \varphi^{\sigma-1} \mu(\varphi) \mathrm{d} \varphi\right]^{1 /(\sigma-1)}
$$

where $M$ is the mass of manufacturing firms (consumption variety), $\mu(\varphi)$ is the productivity distribution, and $\widetilde{\varphi}$ is the average productivity across those firms in the market.

\subsection{Entry, exit and the technological potential}

We now embed this static model into a dynamic framework in continuous time. Entrepreneurs can enter the manufacturing industry subject to a sunk entry cost $f_{e}$. The mass of entrants is given by $M^{E}$ at each point in time. Upon entry, they learn about their productivity level $\varphi$, which is randomly drawn from a common and known distribution. In this paper, we assume that entrants draw their productivity from a Pareto distribution: $G(\varphi)=1-\left(\varphi^{M I N} / \varphi\right)^{k}$, with density $g(\varphi)=k\left(\varphi^{M I N}\right)^{k} \varphi^{-(k+1)}$. Here, $k>1$ is the shape parameter and $\varphi^{M I N}>0$ is the lower bound. ${ }^{6}$

Figure 1 illustrates the fat-tailed shape of the Pareto distribution, and it particularly focuses on the economic meaning of the parameter $\varphi^{M I N}$. We depict two Pareto distribu-

\footnotetext{
${ }^{6}$ This modelling strategy where firms randomly draw their productivity follows Hopenhayn (1992) and Melitz (2003). It has become the seminal approach for studying firm heterogeneity in a general equilibrium model. The Pareto distribution is widely used in this literature, see Bernard et al. (2003) or Melitz and Ottaviano (2008), and also fits empirical firm size distributions fairly well, see Axtell (2001).
} 
tions with different lower bounds $\varphi_{\text {high }}^{M I N}$ and $\varphi_{\text {low }}^{M I N}$. As can be seen, with $\varphi_{\text {high }}^{M I N}$ firms draw their idiosyncratic productivity from a "better" ex ante distribution, as the mass within the entire distribution is shifted to the right. We shall henceforth refer to the parameter $\varphi^{M I N}$ as the country's technological potential.

\section{Figure 1 here}

After learning about the idiosyncratic productivity draw, every firm decides whether to remain active in the market or to exit immediately. If a firm remains active, it earns constant per-period profits as described above. Since a firm cannot cover the per-period fixed costs $f$ when $\varphi$ is too low, it turns out that all firms with a productivity draw below some cutoff level $\varphi^{*}$ decide to exit, while all firms with a draw above $\varphi^{*}$ remain active. As in Melitz (2003), every active firm can then be hit by a bad shock with probability $\delta>0$ at each point of time, which is assumed to be uncorrelated with the firms' productivity draws. If this shock occurs, the firm must shut down. In a stationary equilibrium without time discounting, the mass of entrants which successfully enter the market equals the mass of firms which are forced to exit: $p_{i n} M^{E}=\delta M$, where $p_{i n}=1-G\left(\varphi^{*}\right)$ is the ex ante survival probability of entrants. The endogenous productivity distribution among active firms, $\mu(\varphi)$, is then the conditional ex ante distribution $g(\varphi)$ on the domain $\left(\varphi^{*}, \infty\right]$, which in the present case is also a Pareto distribution with shape parameter $k$.

\subsection{Equilibrium}

Equilibrium can be characterized by two conditions. The free entry condition (FEC) states that the value of entry, $v^{E}=E\left[\sum_{t=0}^{\infty}(1-\delta)^{t} \pi(\varphi)\right]-f_{e}$, is driven to zero. This in turn implies that:

$$
\bar{\pi}=\frac{\delta f_{e}}{1-G\left(\varphi^{*}\right)}=\delta f_{e}\left(\frac{\varphi^{*}}{\varphi^{M I N}}\right)^{k} .
$$

The zero cutoff profit condition (ZCPC) pins down the revenue of the cutoff firm, $r\left(\varphi^{*}\right)=\sigma f$, which by using $r(\widetilde{\varphi}) / r\left(\varphi^{*}\right)=\left(\widetilde{\varphi} / \varphi^{*}\right)^{\sigma-1}$ and $\bar{\pi}=r(\widetilde{\varphi}) / \sigma-f$ leads to:

$$
\bar{\pi}=f\left[\left(\frac{\widetilde{\varphi}}{\varphi^{*}}\right)^{\sigma-1}-1\right]=\frac{f(\sigma-1)}{k+1-\sigma}
$$

with $k>\sigma+1$. Using (FEC) and (ZCPC), we obtain the following equilibrium cutoff productivity under autarky, denoted by $\varphi_{A U T}^{*}$ : 


$$
\varphi_{A U T}^{*}=\Gamma \cdot \varphi^{M I N}, \quad \Gamma \equiv\left(\frac{f(\sigma-1)}{\delta f_{e}(k+1-\sigma)}\right)^{1 / k},
$$

where $\delta f_{e}$ must be sufficiently low and/or $f$ sufficiently high to ensure that $\Gamma>1$, which is required for consistency. Under the Pareto distribution, the average productivity among all active firms is then proportional to the cutoff productivity, $\widetilde{\varphi}_{A U T}=\left(\frac{k}{k+1-\sigma}\right)^{1 /(\sigma-1)} \varphi_{A U T}^{*}$. Furthermore, since aggregate expenditure on varieties, $\beta L$, must equal aggregate revenue of manufacturing firms, $R=M \bar{r}=M r(\widetilde{\varphi})$, we obtain $M=\beta L / \bar{r}$, where $\bar{r}=\sigma(\bar{\pi}+f)$, and consequently $M^{E}=\delta M /\left(1-G\left(\varphi_{A U T}^{*}\right)\right)$. The equilibrium masses of entrants and of surviving firms can thus be expressed explicitly as:

$$
M_{A U T}=\left(\frac{k+1-\sigma}{\sigma k f}\right) \beta L \quad \text { and } \quad M_{A U T}^{E}=\left(\frac{\sigma-1}{\sigma k f_{e}}\right) \beta L .
$$

Finally, using (1), (2), (3) and (4), indirect utility can be computed as follows:

$$
V_{A U T}=y+\beta \ln \varphi_{A U T}^{*}+\frac{\beta}{\sigma-1} \ln L+\kappa_{1},
$$

where $\kappa_{1}=\beta(\ln (\beta \rho)-1)+\frac{\beta}{\sigma-1} \ln (\beta / \sigma f)$ is a constant. Notice that welfare is increasing in the population size $L$ and in the cutoff productivity $\varphi_{A U T}^{*}$. Notice further that an increase in the technological potential leads to a proportional increase in the cutoff and the average productivity, and hence to a welfare gain, while the masses of entrants $M_{A U T}^{E}$ and of surviving firms $M_{A U T}$ are independent of $\varphi^{M I N}$.

To understand this, consider the effect of an increase in the technological potential in the short run. For a given cutoff productivity, this raises the survival probability and, hence, the firms' expected profits. More entry is induced, and more firms appear in the market in the short run. This increases competition and causes exit of the least productive incumbent firms, which in turn raises the cutoff, lowers again the ex ante survival probability, the expected profits and, hence, the value of entry. Under the assumed Pareto distribution, these opposite effects turn out to be of equal magnitude, so that an increase in the technological potential eventually leaves the masses of entrants and surviving firms unaffected in the long run, but increases the cutoff and average productivity among the surviving firms. In other words, an increase in the technological potential does not lead to more but to better firms in the long run equilibrium. These better firms charge lower prices and sell more output, which implies a welfare gain for consumers. Aggregate spending on varieties (i.e., aggregate revenue of manufacturing firms) remains constant at $\beta L$, however. 


\subsection{Investments into basic research and the technological potential}

We now consider the government which levies a lump-sum tax on households and spends the tax revenue on basic research, i.e., on public research foundations, labs, innovation funds, higher education, and so on. In our model, those public research investments lead to an increase in the country's technological potential $\varphi^{M I N}$. Notice that this provision of basic research does not lead to ex post gains for all firms, which still face idiosyncratic risks of business failure. The gains of this policy arise from an ex ante perspective, by improving the premises for domestic entrepreneurs.

For simplicity we normalize the country size to one, $L=1$. The tax rate is denoted by $t$, and since $w=1$ and $L=1$, total tax revenue is given by $T=t$. The variable $T$ also denotes the total public research expenditure, since we assume a balanced budget and an efficient government. The total amount of basic research is denoted by $H(T)$, and in the case of zero expenditure we have $H(0)=0$. For positive expenditure levels, we assume that there are positive but decreasing marginal returns, i.e., $H^{\prime}=\partial H / \partial T>0$, and $H^{\prime \prime}=\partial H^{\prime} / \partial T<0$, and we impose a mild condition on the curvature of this schedule, $\left(H^{\prime}\right)^{2}<-H^{\prime \prime}$, which facilitates our analysis below. The country's technological potential depends positively on the level of basic research, and for concreteness we assume the following specification: ${ }^{7}$

$$
\varphi^{M I N}=\exp \{H(T)\}
$$

which normalizes the technological potential to unity if the country conducts no basic research. It is then straightforward to show that public research expenditure raises the technological potential with decreasing marginal returns:

$$
\varphi^{M I N \prime}=\frac{\partial \varphi^{M I N}}{\partial T}=H^{\prime} \varphi^{M I N}>0 \quad \text { and } \quad \varphi^{M I N \prime \prime}=\frac{\partial \varphi^{M I N \prime}}{\partial T}=\varphi^{M I N}\left[\left(H^{\prime}\right)^{2}+H^{\prime \prime}\right]<0 .
$$

Finally, turning to welfare in the closed economy, we can rewrite expression (5) in the following way by using (3), $L=1$, and $y=1-T$ :

$$
V=1-T+\beta \cdot \ln \varphi^{M I N}(T)+\kappa_{2},
$$

where $\kappa_{2}=\kappa_{1}+\beta \ln \Gamma$ is a constant. The government maximizes this expression with respect to $T$. The condition for a welfare maximum is given by

\footnotetext{
${ }^{7}$ The exponential specification of $\varphi^{M I N}$ in (6) is analytically convenient, but our subsequent results do not crucially hinge on this functional form.
} 


$$
\frac{\partial V}{\partial T}=-1+\beta \frac{\varphi^{M I N \prime}}{\varphi^{M I N}}=-1+\beta H^{\prime}=0,
$$

and from equation (8) we can disentangle the different effects of higher research expenditure on welfare. A higher $T$ raises the technological potential of the country, and thereby the cutoff and the average productivity of firms in the market. This in turn lowers the price index, increases physical consumption of the differentiated varieties, and eventually leads to a welfare gain at the margin $\beta H^{\prime}$. On the other hand, the required lump-sum taxes have a negative unit welfare burden at the margin, since the consumption of the homogenous good is reduced. Using (8), we can state the following result:

Proposition 1 i) The government invests into basic research if $\beta H^{\prime}>1$ for any $0<T<1$, which is the case if consumers have a sufficiently strong preference for varieties $\beta$. ii) The higher $\beta$ is, the higher is the optimal expenditure level and tax rate $T_{A U T}^{*}$.

The proof of part i) follows directly from (8). The comparative static result ii) can be derived by the implicit function theorem. Define $\zeta \equiv H^{\prime}-1 / \beta$, so that we have:

$$
\frac{\partial T^{*}}{\partial \beta}=-\frac{\partial \zeta}{\partial \beta}\left(\frac{\partial \zeta}{T^{*}}\right)^{-1}=-\frac{1}{\beta^{2} H^{\prime \prime}}>0 .
$$

To illustrate proposition 1 , consider the example $H=\sqrt{T}$ which satisfies the aforementioned curvature condition. In that case we have $H^{\prime}=1 /(2 \sqrt{T})$, and solving $H^{\prime}=1 / \beta$ then leads to $T_{A U T}^{*}=\beta^{2} / 4>0$.

Notice that the implementation of this policy affects the manufacturing sector only at the intensive margin in the long run equilibrium: firms become more productive but consumption variety $M_{A U T}$ does not change. In the short run there are instantaneous changes at the extensive margin, however, as we have discussed above. Notice also that this policy affects the resource allocation as it increases the share of the workforce that is employed in the manufacturing sector. ${ }^{8}$

\footnotetext{
${ }^{8}$ In the homogeneous goods sector, aggregate revenue needs to equal aggregate factor payments due to perfect competition. Since the tax lowers the consumers' disposable incomes, and since all income effects of demand accrue in the $A$-sector, this implies that $(1-\beta-t) L=(1-\gamma) L$, where $\gamma$ is the manufacturing employment share. This implies $\gamma=\beta+t$, i.e., higher taxes increase the manufacturing share because aggregate physical output of the manufacturing sector increases which requires more labor there.
} 


\section{Open Economy}

We now consider a scenario with two countries $r=1,2$. These countries are identical in population size $\left(L_{1}=L_{2}=1\right)$, but may differ in their technological potentials. Ultimately we are interested in the determination of the endogenous public research investments that imply those differences, see sections 4 and 5 below. In this section, we first neglect taxes and analyze the open economy equilibrium when the countries' technological potentials are exogenously given. Specifically, we assume that entrants in both countries draw their productivity from a Pareto distribution with the same shape parameter $k$, but country 1 has a higher technological potential than country 2, i.e., $\varphi_{1}^{M I N}>\varphi_{2}^{M I N}$.

In the $A$-sector there are no trade costs. This ensures factor price equalization provided both sectors are active in both countries after trade. In sector $C$ there are two types of trade costs. First, there are per-period fixed costs of exporting, $f_{x}$, that arise if a firm decides to serve the market in the other country. Second, there are the standard iceberg trade costs, i.e., for one unit of output to arrive the firm needs to ship $\tau>1$ units.

The open economy equilibrium can be determined similarly as in the closed economy case, also see Melitz (2003), Demidova (2008), and Pflueger and Suedekum (2009) for more details. The (FEC) remains unchanged for country $r$, and reads as $\bar{\pi}_{r}=\delta f_{e}\left(\varphi_{r}^{*} / \varphi_{r}^{M I N}\right)^{k}$. The (ZCPC) changes due to the fact that firms can now engage in exporting. Ex ante expected profits in country $r$ (conditional on survival) can now be written in the following way: $\bar{\pi}_{r}=\pi_{r}\left(\widetilde{\varphi}_{r}\right)+p_{x r} \pi_{x r}\left(\widetilde{\varphi}_{x r}\right)$, where $p_{x r}=\left(\varphi_{r}^{*} / \varphi_{x r}^{*}\right)^{k}$ is the probability to be an exporter among all active firms from country $r, \pi_{x r}\left(\widetilde{\varphi}_{x r}\right)$ is the corresponding expected export profit level, $\widetilde{\varphi}_{r}$ is the average productivity among all active domestic firms, and $\widetilde{\varphi}_{x r}$ is the average productivity among all exporting firms from country $r$.

Using $\widetilde{\varphi}_{r} / \varphi_{r}^{*}=\widetilde{\varphi}_{x r} / \varphi_{x r}^{*}=\left(\frac{k}{k+1-\sigma}\right)^{1 /(\sigma-1)}$, which holds under the Pareto distribution, the $(\mathrm{ZCPC})$ can be rewritten as follows, $\bar{\pi}_{r}=\frac{f(\sigma-1)}{k+1-\sigma}\left(1+\phi\left(\varphi_{r}^{*} / \varphi_{s}^{*}\right)^{k}\right)$, where $s=\{1,2\} \neq r$ and where $\phi \equiv \tau^{-k}\left(f / f_{x}\right)^{\frac{k+1-\sigma}{\sigma-1}}$ is a measure of trade openness. Substituting the (FEC) into the (ZCPC) then leads to a system of two equations, which can be solved for the equilibrium cutoff productivities in the two countries:

$$
\varphi_{1}^{*}=\left[\frac{\chi\left(1-\phi^{2}\right)}{\chi-\phi}\right]^{\frac{1}{k}} \cdot \Gamma \cdot \varphi_{1}^{M I N} \quad \text { and } \quad \varphi_{2}^{*}=\left[\frac{1-\phi^{2}}{1-\phi \chi}\right]^{\frac{1}{k}} \cdot \Gamma \cdot \varphi_{2}^{M I N}
$$

where $\Gamma>1$ is as defined above, and where $\chi=\left(\varphi_{2}^{M I N} / \varphi_{1}^{M I N}\right)^{k}<1$ measures the relative technological potential of country 2 . We assume $f_{x} \geq f$, which is sufficient for 
$0<\phi<1$. A higher $\phi$ then indicates a higher level of trade openness, with $\phi \rightarrow 1$ and $\phi \rightarrow 0$ capturing the borderline cases of free trade and autarky, respectively. We need to impose that the technological asymmetry is sufficiently small relative to the level of trade openness, namely $\chi>\phi$, to ensure that $\varphi_{r}^{*}>0$ for $r=1,2$. Provided this condition holds, we also have $\varphi_{r}^{*}>\Gamma \cdot \varphi_{r}^{M I N}$ for $r=1,2$, i.e., both countries have a higher cutoff productivity in the open economy than under autarky, which illustrates the selection effect of trade emphasized by Melitz (2003). Furthermore, domestic and export cutoffs can be linked as follows: $\varphi_{x s}^{*}=\Lambda \varphi_{r}^{*}$, with $\Lambda \equiv \tau\left(f_{x} / f\right)^{1 /(\sigma-1)}>1$ due to $f_{x} \geq f$. This, in turn, implies the following ranking of productivity cutoffs: $\varphi_{x 2}^{*}>\varphi_{x 1}^{*}>\varphi_{1}^{*}>\varphi_{2}^{*}$. In words, there is tougher selection in the technologically leading country 1 . Firms from country 1 hence have a higher cutoff and average productivity than firms from country 2.

To complete the description of the equilibrium we need to determine the share of the workforce that is employed in the manufacturing sector in either country. As in Demidova (2008) and Pflueger and Suedekum (2009) we use the aggregate trade balance condition for country 1 to solve for $\gamma_{r}$ for $r=1,2$. In the Appendix we show that they are given by:

$$
\gamma_{1}=\beta\left(\frac{1-2 \phi \chi}{1-\phi \chi}+\frac{\phi}{\chi-\phi}\right) \quad \text { and } \quad \gamma_{2}=\beta\left(\frac{1}{1-\phi \chi}-\frac{\phi}{\chi-\phi}\right) \text {. }
$$

It follows from (11) that $\gamma_{1}=\gamma_{2}=\beta$ if countries are symmetrical $(\chi=1)$, or if trade costs are prohibitive $(\phi \rightarrow 0)$. In the asymmetrical case $(\chi<1)$ we need to impose parameter restrictions such that both sectors are active in both countries after trade, $0<\gamma_{r}<1$ for $r=1,2$. These conditions are spelled out in the Appendix. Using $\gamma_{1}$ and $\gamma_{2}$ as given in (11), it is then straightforward to derive the equilibrium masses of entrants $\left(M_{r}^{E}\right)$, surviving firms $\left(M_{r}\right)$, exporting firms $\left(M_{x r}\right)$, and consumption variety $\left(M_{t r}=M_{r}+M_{x s}\right)$ for both countries - also see the Appendix. The CES price index in the open economy is given by $P_{r}=M_{t r}^{1 /(1-\sigma)} /\left(\rho \widetilde{\varphi}_{t r}\right)$, where $\widetilde{\varphi}_{t r}$ is the average productivity among all (domestic and foreign) firms active in market $r$. Finally, welfare in country $r$ can be written as follows:

$$
V_{r}=1+\beta \cdot \ln \varphi_{r}^{*}\left(\varphi_{r}^{M I N}\right)+\kappa_{1}
$$

which is sufficiently described by the domestic cutoff productivity $\varphi_{r}^{*}$ that, in turn, depends positively on the country's technological potential $\varphi_{r}^{M I N}$, as can be seen from (10). Proposition 2 summarizes the main insights for the case where the two countries differ exogenously in their technological potentials. The proof is also relegated to the Appendix. 
Proposition 2 Suppose country 1 has a higher technological potential than the identically large country 2. Furthermore, assume that the parameter restrictions (A3) hold (see the Appendix), so that $0<\gamma_{r}<1$ for $r=1,2$. The technologically leading country 1 then has: i) more entrants $\left(M_{1}^{E}>M_{2}^{E}\right)$, ii) more surviving firms $\left(M_{1}>M_{2}\right)$, iii) more exporting firms $\left(M_{x 1}>M_{x 2}\right)$ and a higher exporting probability $\left(p_{x 1}>p_{x 2}\right)$, iv) greater consumption diversity $\left(M_{t 1}>M_{t 2}\right)$, v) higher average productivity of domestic firms $\left(\widetilde{\varphi}_{1}>\widetilde{\varphi}_{2}\right)$, vi) higher productivity of firms active in the domestic market $\left(\widetilde{\varphi}_{t 1}>\widetilde{\varphi}_{t 2}\right)$, and vii) higher welfare $\left(V_{1}>V_{2}\right)$.

These results illustrate the benefits of having a higher technological potential in an open economy setting. Those benefits play a crucial role when thinking about the government incentives for basic research investments that will be analyzed in the next section. It is also instructive to consider the role of trade in amplifying those benefits. Specifically, consider two autarkic economies 1 and 2 that are identical, except that country 1 has a higher technological potential. Using (3) the relative cutoff productivity across the two countries, which is a measure for relative welfare, is given by $\left(\varphi_{1}^{*} / \varphi_{2}^{*}\right)=\left(\varphi_{1}^{M I N} / \varphi_{2}^{M I N}\right)>1$ under autarky. When the two countries trade with each other, it follows from (10) that the relative cutoff becomes $\left(\varphi_{1}^{*} / \varphi_{2}^{*}\right)=\Phi \cdot\left(\varphi_{1}^{M I N} / \varphi_{2}^{M I N}\right)$, with $\Phi \equiv[\chi(1-\phi \chi) /(\chi-\phi)]^{(1 / k)}>1$ and $\partial \Phi / \partial \phi>0$. That is, the difference in domestic cutoffs (and, hence, in welfare) is larger with trade than under autarky, and is increasing in the level of trade openness.

The reason is that the technological difference leads to a competitive advantage for the firms from the leading country: Since the market in country 1 has tougher selection, it is more difficult for firms from country 2 to export to the market in 1 than vice versa. This, in turn, reduces the incentives for entry in country 2 and leads to looser selection in that market, which even boosts the expected exporting profits for firms from country 1. The freer trade is, the more important are these considerations, and the stronger is the endogenous welfare difference for a given exogenous disparity in $\varphi_{r}^{M I N}$ across countries.

\section{Basic Research Investments without Spillovers}

We now turn to the analysis of endogenous basic research investments among two identically large countries (with $L_{1}=L_{2}=1$ ). The tax revenue and public expenditure level in country $r$ is denoted by $T_{r}$. Analogous to the closed economy case, the amount of basic research is given by $H\left(T_{r}\right)$ with $H(0)=0, H^{\prime}>0$ and $H^{\prime \prime}<0$. We assume in this section 
that there are no spillovers across countries. That is, the research conducted in country $r$ does not affect the technological potential of the other country $s$, or vice versa. The technological potential in country $r$ is consequently described by $\varphi_{r}^{M I N}=\exp \left\{H\left(T_{r}\right)\right\}$.

\subsection{Nash-Equilibrium}

We first consider the scenario where both countries set their public research investments non-cooperatively. Taking into account (12) and the lump-sum taxes, welfare in country $r$ can be written as follows:

$$
V_{r}=1-T_{r}+\beta \cdot \ln \varphi_{r}^{*}+\kappa_{1}=1-T_{r}+\beta \cdot \ln \left(\varphi_{r}^{M I N}\right)+\frac{\beta}{k} \cdot \ln \left(\frac{\hat{\chi}_{r}}{\hat{\chi}_{r}-\phi}\right)+\kappa_{3},
$$

where $\kappa_{3}=\kappa_{1}+\beta \ln \Gamma+\frac{\beta}{k} \ln \left(1-\phi^{2}\right)$ is a constant and $\hat{\chi}_{r}=\left(\varphi_{s}^{M I N} / \varphi_{r}^{M I N}\right)^{k}$ is a measure of the relative technological potential of country $r$, with $\hat{\chi}_{r}>\phi$ to ensure $\varphi_{r}^{*}>0$ for $r=1,2$. The condition for a welfare optimum is given by:

$$
\frac{\partial V_{r}}{\partial T_{r}}=-1+\beta H^{\prime}\left(T_{r}\right)+\frac{\phi \beta H^{\prime}\left(T_{r}\right)}{\left(\exp \left\{H\left(T_{s}\right)-H\left(T_{r}\right)\right\}\right)^{k}-\phi}=0 .
$$

There exists a symmetric Nash-equilibrium where both countries set the same tax rate $T_{r}=T_{s}=T$. In that case, (14) simplifies to:

$$
\frac{\partial V}{\partial T}=-1+\beta H^{\prime}+\underbrace{\frac{\phi}{(1-\phi)} \beta H^{\prime}}_{\text {trade effect }}=0 .
$$

Using (15) we can disentangle the different effects of higher research investments on welfare. First, the required lump-sum taxes imply a marginal cost equal to unity. Second, the investments increase the own technological potential, which tends to raise the domestic cutoff and average productivity as well as welfare. This is the marginal benefit $\beta H^{\prime}$ that we have already discussed in the closed economy case. Finally, there is a new "trade effect", $\phi \beta H^{\prime} /(1-\phi)$, which depicts the marginal effect of the research investments on the relative technological potential of the two countries. As discussed above, a higher relative technological potential is beneficial for country $r$, as it leads to a competitive advantage for domestic firms relative to their competitors from the other country $s$. This mirrors the strategic incentive for governments to invest into basic research. The higher the trade openness $\phi$ is, the greater is the governments' incentive to give domestic firms 
this competitive advantage. Trade liberalization thus increases the research investments in the Nash-equilibrium. To see this analytically, define $\zeta=\beta H^{\prime} /(1-\phi)-1$ and use the implicit function theorem to obtain:

$$
\frac{\partial T}{\partial \phi}=-\frac{\partial \zeta}{\partial \phi}\left(\frac{\partial \zeta}{\partial T}\right)^{-1}=-\frac{H^{\prime}}{(1-\phi) H^{\prime \prime}}>0
$$

We can hence state the following result:

Proposition 3 i) The tax and public research expenditure in the open economy Nashequilibrium with two identical countries, $T^{*}$, is higher than under autarky. ii) Trade liberalization leads to higher taxes and public research expenditure $T^{*}$.

To illustrate proposition 3, consider again the example where $H_{r}=\sqrt{T_{r}}$. We then have $H^{\prime}=1 /(2 \sqrt{T})$, and solving (15) which reads as $H^{\prime}=(1-\phi) / \beta$, leads to $T^{*}=\beta^{2} /\left(4(1-\phi)^{2}\right)$ in the Nash-equilibrium, which is larger than $T_{A U T}^{*}$ derived above.

\subsection{Cooperative Policy}

Now consider the scenario where the countries cooperatively set their policies. Given the quasi-linear preferences with identical marginal utility of income, joint welfare can be precisely measured by a utilitarian social welfare function. Joint welfare $\Omega$ is given by:

$$
\Omega=V_{1}+V_{2}=2-T_{1}-T_{2}+\beta \ln \varphi_{1}^{M I N}+\beta \ln \varphi_{2}^{M I N}+\frac{\beta}{k} \cdot \ln \left[\frac{\hat{\chi_{1}} \hat{\chi}_{2}}{\left(\hat{\chi}_{1}-\phi\right)\left(\hat{\chi_{2}}-\phi\right)}\right]+2 \kappa_{3}
$$

where the interaction term in squared parentheses encapsulates the cross-country externalities of the research investments. The condition for a welfare optimum is given by

$$
\frac{\partial \Omega}{\partial T_{r}}=-1+\beta H^{\prime}\left(T_{r}\right)+\frac{\phi \beta H^{\prime}\left(T_{r}\right)}{\left(\exp \left\{H\left(T_{s}\right)-H\left(T_{r}\right)\right\}\right)^{k}-\phi}-\frac{\phi \beta H^{\prime}\left(T_{r}\right)}{\left(\exp \left\{H\left(T_{r}\right)-H\left(T_{s}\right)\right\}\right)^{k}-\phi}=0
$$

for $r=1,2$. Imposing $T_{1}=T_{2}=T$ due to symmetry, the last two terms on the right hand side of this equation just cancel out, so that the simplified first-order condition for the cooperative policy simply reads as

$$
\frac{\partial \Omega}{\partial T}=-1+\beta H^{\prime}=0
$$


We can hence state

Proposition 4 Consider two identical open economies that cooperatively set their basic research investments. Without cross-country spillovers the cooperative policy is equivalent to the policy that each country would choose under autarky.

A comparison of propositions 3 and 4 directly implies that the Nash-equilibrium policy is characterized by over-investments into basic research from a social perspective, and that trade liberalization exacerbates this problem. The reason is that every government tries to give domestic firms a competitive advantage in trade, but the effects of the own research investments are just offset by the impact of the foreign investments. When coordinating the research expenditures, those negative cross-country externalities are internalized. With policy coordination the average productivity of firms is thus lower than in the Nashequilibrium, but this is optimal since the excessively high research investments in the non-cooperative scenario imply too little consumption of the homogenous good.

\section{Basic Research Investments with Spillovers}

We now turn to the analysis where the basic research conducted in one country does affect the technological potential of the other country. We assume that the technological potential in country $r$ is described by $\varphi_{r}^{M I N}=\exp \left\{H\left(T_{r}\right)+\phi \cdot F\left(T_{s}\right)\right\}$, where the amount of basic research in the foreign country $s$ is given by $F\left(T_{s}\right)$. Analogously as before we assume that $F(0)=0, F^{\prime}>0$ and $F^{\prime \prime}<0$. Notice that the strength of the spillover depends on the level of trade openness, $\phi$, which we consider to be a broad measure of the level of economic integration between the two countries. ${ }^{9}$

\subsection{Nash-Equilibrium}

Considering first the non-cooperative policy determination, the necessary condition for a welfare maximum can now be written as

$$
\frac{\partial V_{r}}{\partial T_{r}}=-1+\beta H^{\prime}\left(T_{r}\right)+\frac{\phi \beta H^{\prime}\left(T_{r}\right)-\phi^{2} \beta F^{\prime}\left(T_{r}\right)}{\left(\exp \left\{H\left(T_{s}\right)-H\left(T_{r}\right)+\phi F\left(T_{r}\right)-\phi F\left(T_{s}\right)\right\}\right)^{k}-\phi}=0 .
$$

\footnotetext{
${ }^{9}$ See Adams (1990), Jaffe (1989) and Branstetter (2001) for empirical evidence that knowledge spillovers (e.g. from patent citations) exhibit a rapid spatial decay, but flow more rapidly across ecomically well integrated areas.
} 
There exists a symmetric Nash-equilibrium policy where both countries set the same tax rate $T_{r}=T_{s}=T$, in which case (19) simplifies to

$$
\frac{\partial V}{\partial T}=-1+\overbrace{\frac{1}{(1-\phi)} \beta H^{\prime}-\underbrace{\frac{\phi^{2}}{(1-\phi)} \beta F^{\prime}}_{\text {spillover effect }}}^{\text {marginal benefit }}=0 .
$$

It follows from (20) that the marginal benefit is composed of two terms, i) the term $\beta H^{\prime} /(1-\phi)$ that is already known from the case without spillovers (see section 4.1), and the new "spillover effect". Both terms increase in trade openness but have opposite signs. Comparing (20) with (15), it immediately follows that the Nash-equilibrium expenditure $T^{*}$ is lower with direct cross-country spillovers than without it. The reason is that the competitive advantage for domestic firms is smaller when foreign entrepreneurs also benefit from the domestic public research expenditure. ${ }^{10}$

With higher trade openness this "free rider" problem becomes more severe, which dampens the government incentive to invest. On the other hand, freer trade raises the term $\beta H^{\prime} /(1-\phi)$ which tends to increase the Nash-equilibrium expenditure. The question is thus if trade liberalization leads to an overall increase or decrease of $T^{*}$ when direct crosscountry spillovers play a role. To address this question, let $\Delta \equiv H^{\prime}-F^{\prime}$. One would typically expect that domestic research expenditure has a stronger impact on the domestic than on the foreign technological potential, i.e., $\Delta>0$. We refer to this case as the "weak spillover" scenario. For this case it is straightforward to show that the Nash-equilibrium expenditure level is increasing in $\phi$. Define $\zeta=\frac{\beta}{1-\phi} H^{\prime}-\frac{\beta \phi^{2}}{1-\phi} F^{\prime}-1$ and use the implicit function theorem to obtain:

$$
\frac{\partial T}{\partial \phi}=\frac{\partial \zeta}{\partial \phi}\left(\frac{\partial \zeta}{\partial T}\right)^{-1}=\frac{H^{\prime}+(-2+\phi) \phi F^{\prime}}{(1-\phi)\left(\phi^{2} F^{\prime \prime}-H^{\prime \prime}\right)}=-\frac{H^{\prime}\left(1-\phi^{2}\right)+\Delta(2-\phi) \phi}{(1-\phi)\left(1-\phi^{2}\right) H^{\prime \prime}} .
$$

This term is unambiguously positive with $\Delta>0$. Nevertheless, there may be instances where domestic research investments have a stronger impact on the foreign than to the home country. ${ }^{11}$ For situations like this we have $\Delta<0$ and refer to it as the "strong spillover" case. Solving $\partial T / \partial \phi=0$ for $\phi$ leads to $\bar{\phi}=1-\sqrt{-\Delta / F^{\prime}}$ with $\bar{\phi}<1$ if

\footnotetext{
${ }^{10}$ This parallels the well known result that single firms have lower incentives to invest into R\&D when there are direct spillovers to other firms, see Spence (1984) as a seminal reference.

${ }^{11}$ What we have in mind here are small countries like Hong Kong with a strong inflow of Chinese and other foreign students. Depending on the degree of economic integration, research investments in Hong Kong may actually lead to stronger effects in those foreign countries than in Hong Kong itself.
} 
$\Delta<0$. The Nash-equilibrium expenditure level $T^{*}$ is increasing (decreasing) in $\phi$ if the level of trade openness is below (above) $\bar{\phi}$. In other words, there is a hump-shaped pattern between $\phi$ and $T^{*}$ when $\Delta<0$, and the downward-sloping range starts earlier the stronger the spillover is (the lower $\Delta$ is). Summing up, we can state the following result:

Proposition 5 i.) For any given $\phi$ the Nash-equilibrium research expenditure, $T^{*}$, is lower with direct cross-country spillovers than without it. ii.) Trade liberalization increases $T^{*}$ if spillovers are weak. iii.) In the case of strong spillovers, trade liberalization first leads to an increase and then to a decrease of $T^{*}$.

To illustrate this result, suppose that $H=\sqrt{T}$ and $F=s \sqrt{T}$, where $s$ denotes the strength of the spillover. With $0<s<1$ we have a weak, and with $s>1$ we have a strong spillover.

Solving (20) yields $T^{*}=\frac{\beta^{2}\left(1-s \phi^{2}\right)^{2}}{4(1-\phi)^{2}}$, which achieves a global maximum at $\phi=\sqrt{1 / s}$. Hence, there only exists a maximum for $T^{*}$ in the admissible range $0<\phi<1$ if $s>1$, while $T^{*}$ is monotonically increasing in $\phi$ for all $s<1$.

\subsection{Cooperative Policy}

Finally, turning to the cooperative policy determination for the case with direct crosscountry spillovers, it follows from (17) that the condition for a welfare optimum now reads as

$$
\frac{\partial \Omega}{\partial T_{r}}=-1+\beta H^{\prime}\left(T_{r}\right)+\frac{\phi \beta H^{\prime}\left(T_{r}\right)-\phi^{2} \beta F^{\prime}\left(T_{r}\right)}{\exp \{\cdot\}-\phi}+\frac{\phi \beta F^{\prime}\left(T_{r}\right)-\phi \beta H^{\prime}\left(T_{r}\right) \exp \{\cdot\}}{1-\exp \{\cdot\} \phi}=0,
$$

for $r=1,2$, where the argument of the exponential function is suppressed to simplify notation and is given by $\exp \{\cdot\}=\exp \left\{k\left(H\left(T_{s}\right)-H\left(T_{r}\right)+\phi F\left(T_{r}\right)-\phi F\left(T_{s}\right)\right)\right\}$. Imposing $T_{r}=T_{s}=T$ due to symmetry, this expression simplifies to

$$
\frac{\partial \Omega}{\partial T}=-1+\beta H^{\prime}+\beta \phi F^{\prime}=0
$$

Define $\zeta=\beta H^{\prime}+\beta \phi F^{\prime}-1$ and use the implicit function theorem to derive $\partial T^{o p t} / \partial \phi=-F^{\prime} /\left(\phi F^{\prime \prime}+H^{\prime \prime}\right)>0$. We hence have

Proposition 6 Consider two identical open economies that cooperatively set their basic research investments. With direct cross-country spillovers, trade liberalization leads to a higher optimal research expenditure $T^{\text {opt }}$. 
The reason is that investments not only improve the domestic technological potential, but they now also generate a positive externality for the foreign entrepreneurs. The latter effect is stronger the higher the level of trade openness is. In comparison to the Nashequilibrium policy, the spillover thus does not dampen the incentive to invest. Exactly the opposite it true. Due to the positive externality, the optimal research expenditure level is actually higher with than without spillovers. To compare the cooperative with the Nash-equilibrium policy, we can rewrite the first-order conditions (20) and (23) as follows:

$$
\frac{\partial V}{\partial T}=-1+\beta H^{\prime}+\beta \phi F^{\prime}+\frac{\phi}{1-\phi} \beta \Delta=0 \quad \text { and } \quad \frac{\partial \Omega}{\partial T}=-1+\beta H^{\prime}+\beta \phi F^{\prime}=0 .
$$

Those expressions differ only in the last term of $\partial V / \partial T$. The sign of this term depends on $\Delta$, i.e., on whether the spillover is weak or strong. If the spillover is weak (strong), the public research expenditure in the Nash-equilibrium, $T^{*}$, is higher (lower) than the optimal expenditure level, $T^{\text {opt }}$. Summing up, we have

Proposition 7 i.) The Nash-equilibrium is characterized by over-investments into basic research if the direct cross-country spillover is weak, $T^{*}>T^{o p t}$ with $\Delta>0$. ii.) When the spillover is strong, there are too little basic research investments from a social perspective in the Nash-equilibrium, $T^{*}<T^{o p t}$ with $\Delta<0$.

This result represents the interplay between two cross-country externalities. Domestic basic research hurts the foreign entrepreneurs as it gives domestic firms a competitive advantage in trade. On the other hand there is a positive impact on the foreign technological potential. Depending on which impact dominates there is either a net over-investment or a net under-investment problem from a social perspective, and proposition 7 shows that the latter arises when the spillover is strong.

\section{Conclusion}

In this paper we have developed a two-country model with heterogeneous firms where governments can invest into basic research. These public research investments improve the country's technological potential and thereby benefit domestic entrepreneurs who start up a business. They do not equally benefit all domestic firms from an ex post perspective, however, since firms are still exposed to idiosyncratic risks of business failure. There are two motives for this public research policy. First, the benevolent motive (present 
already in an autarky scenario) is to tighten firm selection which in turn raises the average productivity of firms in the market, decreases the average price, and ultimately benefits consumers. Second, there is a strategic motive in an open economy setting, as firms obtain a competitive advantage in trade when the domestic country has a higher technological potential. Due to this strategic motive, countries invest too much from a social perspective, so that there are welfare gains from coordinating public research investments. This overinvestment problem only disappears, and turns to an under-investment problem, when there are sufficiently strong direct spillovers of research investments across countries.

We observe in the data that most OECD countries have increased public research spending over the last ten years. Our model provides a possible theoretical rationale for this empirical observation. The recent decade was certainly characterized by falling trade barriers and a deepening of globalization. The model predicts that this tendency of higher trade freeness raises the strategic incentives for governments to invest into basic research, and it is thus well consistent with the stylized facts. From a normative perspective, however, it is unclear if this tendency is welfare improving. Our model predicts that global competition induces single countries to over-invest into basic research, and trade liberalization tends to exacerbate this problem.

However, in practice further trade liberalization probably also leads to a stronger diffusion of basic knowledge across countries. That is, cross-country knowledge spillovers may also become more important as globalization proceeds. These spillovers have two basic consequences: They lower the incentives for single countries to invest due to a standard free rider problem, but they also tend to reduce the over-investment problem. From a policy perspective, the optimal regime seems to be one where countries coordinate their research investments in order to internalize cross-country externalities, and where they also try to foster the cross-country diffusion of the knowledge created in those coordinated public research efforts.

\section{References}

Adams, J. (1990), Fundamental Stocks of Knowledge and Productivity Growth, Journal of Political Economy 98: 673-702.

Aw, B.Y., S. Chung and M.J. Roberts (2000), Productivity and Turnover in the Export Market: Micro-Level Evidence from the Republic of Korea and Taiwan (China), World Bank Economic Review 14: 65-90. 
Axtell, R.L. (2001), Zipf Distribution of US Firm Sizes, Science 293: 1818-1820.

Bénassy-Quéré, A., N. Gobalraja and A. Trannoy (2007), Tax and Public Input Competition, Economic Policy 22: 385-430.

Bernard, A.B., J. Eaton, J.B. Jensen and S. Kortum (2003), Plants and Productivity in International Trade, American Economic Review 93: 1268-1290.

Bernard, A.B. and J.B. Jensen (1999), Exceptional Exporter Performance: Cause, Effect or Both?, Journal of International Economics 47: 1-25.

Branstetter, L. (2001), Are Knowledge Spillovers International or Intranational in Scope? Microeconometric Evidence from the U.S. and Japan, Journal of International Economics 53: 53-79.

Chor, D. (2009), Subsidies for FDI: Implications from a Model with Heterogeneous Firms, Journal of International Economics 78: 113-125.

Clerides, S.K., S. Lack and J.R. Tybout (1998), Is Learning by Exporting Important? Micro-Level Evidence from Colombia, Mexico and Morocco, The Quarterly Journal of Economics 113: 903-947.

Cohen, W.M. and D.A. Levinthal (1989), Innovation and Learning: The Two Faces of R\&D, The Economic Journal 99: 569-596.

Council of the European Union (2008), Presidency Conclusions, Brussels 13/14 March 2008.

Davies, R. and C. Eckel (2009), Tax Competition for Heterogeneous Firms with Endogenous Entry, American Economic Journal - Economic Policy 2: 77-102.

Demidova, S. (2008), Productivity Improvements and Falling Trade Costs: Boon or Bane?, International Economic Review 4: 1437-1462.

Demidova, S. and A. Rodriguez-Clare (2009), Trade Policy under Firm-Level Heterogeneity in a Small Economy, Journal of International Economics 78: 100-112.

Geroski, P. (1995), What do we know about entry?, International Journal of Industrial Organization 13: 421-440. 
González, X. and C. Pazó (2008), Do Public Subsidies Stimulate Private R\&D Spending?, Research Policy 37: 371-389.

Grossman, G. and E. Helpman (1991), Quality Ladders in the Theory of Economic Growth, Review of Economic Studies 58: 43-61.

Hopenhayn, H. (1992), Entry, Exit and Firm Dynamics in Long Run Equilibrium, Econometrica 60: 1127-1150.

Jaffe, A. (1989), The Real Effects of Academic Research, American Economic Review 79: 957-970.

Jaffe, A., M. Fogarty, and B. Banks (1998), Evidence from Patents and Patent Citations in the Impact of NASA and Other Federal Labs on Commercial Innovation, Journal of Industrial Economics 46: 183-204.

Kleer, R. (2008), Government R\&D Subsidies as a Signal for Private Investors, Research Policy 39: 1361-1374.

Krautheim, S. and T. Schmidt-Eisenlohr (2010), Heterogeneous Firms, Profit-shifting FDI and International Tax Competition, Journal of Public Economics 95: 122-133.

Krugman, P. (1980), Scale Economies, Product Differentiation and the Pattern of Trade, American Economic Review 70: 950-959.

Leydesdorff, L. and P. Zhou (2006), The Emergence of China as a Leading Nation in Science, Research Policy 35: 83-104.

Melitz, M. (2003), The Impact of Trade on Intra-Industry Reallocations and Aggregate Industry Productivity, Econometrica 71: 1695-1725.

Melitz, M. and G. Ottaviano (2008), Market Size, Trade and Productivity, Review of Economic Studies 75: 715-731.

Nelson, R. (1959), The Simple Economics of Basic Scientific Research, Journal of Political Economy 67: 297-306.

O’Mahony, M. and M. Vecchi (2009), R\&D Knowledge Spillovers and Company Productivity Performance, Research Policy 38: 35-44. 
Pflueger, M. and J. Suedekum (2009), Subsidizing Firm Entry in Open Economies, IZA DP No. 4384.

Spence, M. (1984), Cost Reduction, Competition, and Industry Performance, Econometrica 52: 101-121.

Zodrow, G.R. and P. Mieszkowski (1986), Pigou, Tiebout, Property Taxation and the Underprovision of Local Public Goods, Journal of Urban Economics 19: 356-370. 


\section{Appendix: Open Economy Model}

\section{Equilibrium Firm Masses in the Open Economy}

Aggregate earnings in the manufacturing sector must equal aggregate revenue of manufacturing firms in each country, $\gamma_{r}=M_{r} \bar{r}_{r}$, where $\bar{r}_{r}=r_{r}\left(\widetilde{\varphi}_{r}\right)+p_{x r} r_{x r}\left(\widetilde{\varphi}_{x r}\right)$. This yields $M_{r}=\gamma_{r} / \bar{r}_{r}$ for $r=1,2$. Plugging these terms into the aggregate trade balance condition for country $1, M_{1} p_{x 1} r_{x 1}\left(\widetilde{\varphi}_{x 1}\right)=M_{2} p_{x 2} r_{x 2}\left(\widetilde{\varphi}_{x 2}\right)+(1-\beta)-\left(1-\gamma_{1}\right)$, and into the analogous trade balance condition for country 2 yields:

$$
\frac{\gamma_{1}}{1+b_{1}}=\frac{\gamma_{2}}{1+b_{2}}+\gamma_{1}-\beta \quad \frac{\gamma_{2}}{1+b_{2}}=\frac{\gamma_{1}}{1+b_{1}}+\gamma_{2}-\beta
$$

where

$$
\begin{aligned}
& b_{1}=\frac{r_{1}\left(\widetilde{\varphi}_{1}\right)}{p_{x 1} r_{x 1}\left(\widetilde{\varphi}_{x 1}\right)}=\frac{\tau^{\sigma-1}}{p_{x 1}}\left(\frac{\widetilde{\varphi}_{1} \varphi_{2}^{*}}{\varphi_{1}^{*} \widetilde{\varphi}_{x 1}}\right)^{\sigma-1}=\frac{1}{\phi}\left(\frac{\varphi_{2}^{*}}{\varphi_{1}^{*}}\right)^{k}=\frac{1}{\phi}\left(\frac{\chi-\phi}{1-\phi \chi}\right) \\
& b_{2}=\frac{r_{2}\left(\widetilde{\varphi}_{2}\right)}{p_{x 2} r_{x 2}\left(\widetilde{\varphi}_{x 2}\right)}=\frac{\tau^{\sigma-1}}{p_{x 2}}\left(\frac{\widetilde{\varphi}_{2} \varphi_{1}^{*}}{\varphi_{2}^{*} \widetilde{\varphi}_{x 2}}\right)^{\sigma-1}=\frac{1}{\phi}\left(\frac{\varphi_{1}^{*}}{\varphi_{2}^{*}}\right)^{k}=\frac{1}{\phi}\left(\frac{1-\phi \chi}{\chi-\phi}\right) .
\end{aligned}
$$

Solving (A1) for $\gamma_{r}$ yields:

$$
\gamma_{1}=\beta \frac{\left(1+b_{1}\right)\left(1-b_{2}\right)}{1-b_{1} b_{2}} \quad \gamma_{2}=\beta \frac{\left(1-b_{2}\right)\left(1-b_{1}\right)}{1-b_{1} b_{2}}
$$

and plugging in $b_{1}$ and $b_{2}$ then leads to the expressions given in (11). To ensure that $0<\gamma_{r} \leq 1$ for $r=1,2$ we need to impose the following parameter restrictions:

$$
0<\beta<\beta_{\max } \equiv \frac{(\chi-\phi)(1-\phi \chi)}{\chi\left(1+\phi^{2}-2 \phi \chi\right)} \quad \text { and } \quad \frac{2 \phi}{\left(1+\phi^{2}\right)}<\chi<1 .
$$

The conditions in (A3) require that the per-capita manufacturing expenditure, $\beta$, is sufficiently small, and they put an even stricter limit on the degree of asymmetry, $\chi$, relative to the level of trade openness, $\phi$, than the previously mentioned condition $\phi<\chi$, which is automatically satisfied when (A3) holds. Using $M_{r}=\gamma_{r} / \bar{r}_{r}$ and $\gamma_{1}, \gamma_{2}$ then yields the masses of entrants, surviving firms, and exporting firms for both countries:

$$
\begin{aligned}
& M_{1}^{E}=\frac{\delta M_{1}}{\left(\varphi_{1}^{M I N} / \varphi_{1}^{*}\right)^{k}}=\frac{(\sigma-1) \beta}{\sigma k f_{e}} \frac{\chi\left(1+\phi^{2}-2 \phi \chi\right)}{(\chi-\phi)(1-\phi \chi)} \\
& M_{2}^{E}=\frac{\delta M_{2}}{\left(\varphi_{2}^{M I N} / \varphi_{2}^{*}\right)^{k}}=\frac{(\sigma-1) \beta}{\sigma k f_{e}} \frac{\left(\chi\left(1+\phi^{2}\right)-2 \phi\right)}{(\chi-\phi)(1-\phi \chi)} \\
& M_{1}=\frac{\gamma_{1}}{\sigma\left(\bar{\pi}_{1}+f+p_{x 1} f_{x}\right)}=\frac{(k+1-\sigma) \beta}{\sigma k f} \frac{1+\phi^{2}-2 \phi \chi}{\left(1-\phi^{2}\right)(1-\phi \chi)}
\end{aligned}
$$




$$
\begin{aligned}
& M_{2}=\frac{\gamma_{2}}{\sigma\left(\bar{\pi}_{2}+f+p_{x 2} f_{x}\right)}=\frac{(k+1-\sigma) \beta}{\sigma k f} \frac{\left(\chi\left(1+\phi^{2}\right)-2 \phi\right)}{\left(1-\phi^{2}\right)(\chi-\phi)} \\
& M_{x 1}=\left(\frac{\varphi_{1}^{*}}{\Lambda \varphi_{2}^{*}}\right)^{k} M_{1}=\frac{(k+1-\sigma) \beta}{\sigma k f_{x}} \frac{\phi\left(1+\phi^{2}-2 \phi \chi\right)}{\left(1-\phi^{2}\right)(\chi-\phi)} \\
& M_{x 2}=\left(\frac{\varphi_{2}^{*}}{\Lambda \varphi_{1}^{*}}\right)^{k} M_{2}=\frac{(k+1-\sigma) \beta}{\sigma k f_{x}} \frac{\phi\left(\chi\left(1+\phi^{2}\right)-2 \phi\right)}{\left(1-\phi^{2}\right)(1-\phi \chi)}
\end{aligned}
$$

From these expressions, the mass of firms active in country $r, M_{t r}=M_{r}+M_{x s}$, (i.e., consumption variety) can then be easily obtained.

\section{Proof of Proposition 2}

Consider the scenario in which country 1 has a higher technological potential than country 2, i.e., $\varphi_{1}^{M I N}>\varphi_{2}^{M I N}$. Under the parameter restrictions (A3) we can show that:

$$
\begin{aligned}
\text { (i) } \quad \frac{M_{1}^{E}}{M_{2}^{E}}=\frac{\chi\left(1+\phi^{2}-2 \phi \chi\right)}{\chi+\phi(\phi \chi-2)}>1 \\
\text { (ii) } \frac{M_{1}}{M_{2}}=\frac{(\chi-\phi)\left(1+\phi^{2}-2 \phi \chi\right)}{(1-\phi \chi)(\chi+\phi(\phi \chi-2))}>1 \\
\text { (iii) } \frac{M_{x 1}}{M_{x 2}}=\frac{(1-\phi \chi)\left(1+\phi^{2}-2 \phi \chi\right)}{(\chi-\phi)(\chi+\phi(\phi \chi-2))}>1 \text { and } \\
\frac{p_{x 1}}{p_{x 2}}=\frac{(1-\phi \chi)^{2}}{(\chi-\phi)^{2}}>1 \\
\text { (iv) } \frac{M_{t 1}}{M_{t 2}}=\frac{(\chi-\phi)\left(f_{x}\left(1+\phi^{2}-2 \phi \chi\right)+f \phi(\chi+\phi(\phi \chi-2))\right)}{(1-\phi \chi)\left(f \phi\left(1+\phi^{2}-2 \phi \chi\right)+f_{x}(\chi+\phi(\phi \chi-2))\right)}>1 .
\end{aligned}
$$

Furthermore, since the relative cutoff productivities can be written as follows:

$$
\frac{\varphi_{1}^{*}}{\varphi_{2}^{*}}=\Phi \cdot \frac{\varphi_{1}^{M I N}}{\varphi_{2}^{M I N}} \quad \text { with } \quad \Phi \equiv[\chi(1-\phi \chi) /(\chi-\phi)]^{(1 / k)}>1
$$

it follows directly that $(v) \tilde{\varphi}_{1} / \tilde{\varphi}_{2}=\Phi \cdot\left(\varphi_{1}^{M I N} / \varphi_{2}^{M I N}\right)>1$, $(v i) \tilde{\varphi}_{t 1}>\tilde{\varphi}_{t 2}$, since $\tilde{\varphi}_{1}>\tilde{\varphi}_{2}$ and $\tilde{\varphi}_{x 2}>\tilde{\varphi}_{x 1}$, and $(v i i) V_{1}>V_{2}$, since $V_{r}$ is proportional to $\varphi_{r}^{*}$. 
Figure 1: Pareto distribution with different lower bounds

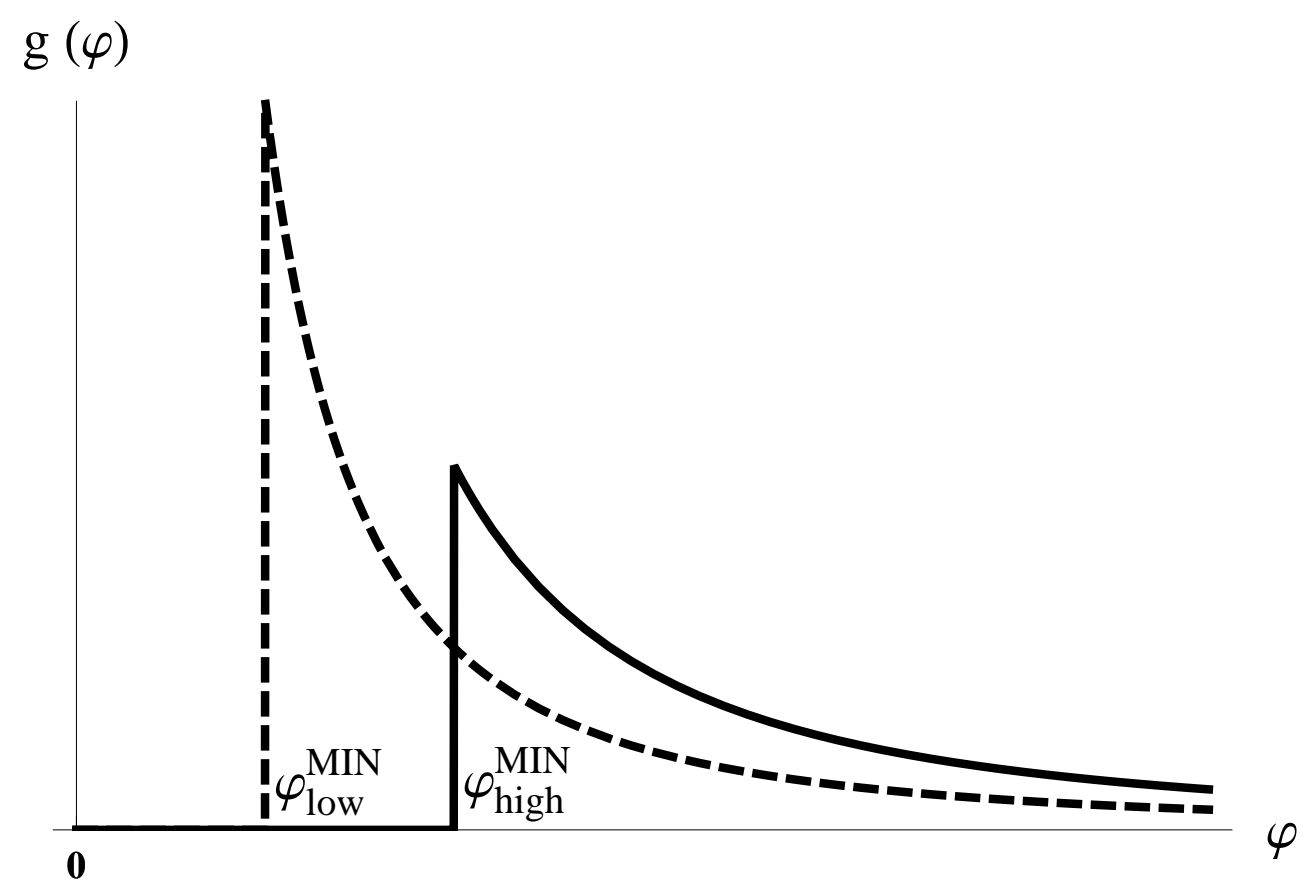


Table 1: R\&D spending in selected OECD countries

\begin{tabular}{|l|c|c|c|c|}
\hline & \multicolumn{2}{|c|}{$\mathbf{2 0 0 7 / 2 0 0 8}$} & \multicolumn{2}{c|}{ 2000 } \\
\hline & GERD & PubGERD & GERD & PubGERD \\
\% GDP & per capita in USD & \% GDP & per capita in USD \\
\hline United States & 2.8 & 381.3 & 2.4 & 293.3 \\
Norway*** & 1.6 & 355.5 & 1.6 & 291.8 \\
Sweden $^{* * *}$ & 3.6 & 352.8 & 3.4 & 257.6 \\
Finland & 3.5 & 334.1 & 3.4 & 276.1 \\
Australia**,*** & 2.1 & 305.4 & 1.5 & 245.7 \\
Denmark & 2.7 & 288.0 & 2.2 & 254.7 \\
Switzerland* & 2.9 & 280.7 & 2.6 & 227.0 \\
France & 2.0 & 276.1 & 2.0 & 254.5 \\
Korea & 3.5 & 272.6 & 2.2 & 156.2 \\
Japan & 3.4 & 258.2 & 3.0 & 261.3 \\
Netherlands & 1.7 & 253.6 & 1.9 & 261.8 \\
Belgium & 1.9 & 241.7 & 2.0 & 212.4 \\
United Kingdom & 1.9 & 241.5 & 1.6 & 181.5 \\
Germany & 2.5 & 239.3 & 2.4 & 205.6 \\
Luxembourg & 1.6 & 206.7 & 1.7 & 96.1 \\
New Zealand & 1.2 & 176.8 & 1.0 & 157.3 \\
Spain & 1.3 & 170.9 & 0.8 & 110.1 \\
Italy*** & 1.1 & 164.5 & 1.0 & 133.2 \\
Czech Republic & 1.5 & 146.2 & 1.2 & 96.2 \\
Portugal & 1.2 & 121.0 & 0.8 & 117.0 \\
Slovak Republic & 0.5 & 52.2 & 0.6 & 25.4 \\
\hline Weighted average & 2.5 & 286.9 & 2.1 & 232.5 \\
\hline
\end{tabular}

Source: Own calculations based on OECD data. The table reports: i) gross domestic expenditure on R\&D (GERD) as a share of GDP for the years 2007/08 and 2000; ii) absolute public research expenditure per capita in constant USD prices of 2000. These amounts are calculated as follows: From the absolute GERD we subtract the business expenditure on research and development (BERD) excluding direct and indirect government subsidies to private firms. This leaves us with the public expenditure on research and development (PubGERD) which we then divide by population size in the respective year. In the last row we report the average across all countries weighted by population size. Due to missing data we use different years in some cases: ${ }^{*}$ data for 2004 and ${ }^{* *}$ data for $2006,{ }^{* * *}$ data for 1999. 